\title{
Exploring refined conditions for reprogramming cells by recombinant Oct4 protein
}

\author{
MARC THIER, BERNHARD MÜNST and FRANK EDENHOFER* \\ Stem Cell Engineering Group, Institute of Reconstructive Neurobiology, University of Bonn - Life \& Brain \\ Center and Hertie Foundation, Bonn, Germany.
}

\begin{abstract}
The generation of human induced pluripotent stem (iPS) cells would represent an appealing option for the derivation of pluripotent patient-specific cells, as no embryos or oocytes are required. However, crucial safety issues have to be addressed in order to create human iPS cells that are clinically useful, as the classical iPS technique involves permanent genetic manipulation that may result in tumor formation. Various experimental strategies have been suggested to accomplish transgene-free derivation of iPS cells, including the use of non-integrating viruses, site specific recombinases to excise transgenes after reprogramming, or RNA transfection. Protein transduction, i.e. the direct delivery of biologically active proteins into cells, has been employed to generate iPS cells but has been found to have very low efficiency. In fact, success of protein transduction is limited by poor stability and solubility of recombinant factors, as well as their poor endosomal release. We recently reported the generation of cell-permeant versions of Oct4 and Sox2 and showed that both can be delivered intracellularly as biologically active proteins. Here we explore conditions for enhanced protein stabilization and delivery into somatic cells. Employing optimized conditions, we demonstrate that Oct4 protein delivery can substitute for Oct4 virus, yielding iPS derivation efficacy comparable to a four virus transduction protocol. The number of colonies is strictly dependent on the dose and duration of cell-permeant Oct4 exposure. We expect our transduction system to reach a thus far unattained level of control over reprogramming activity, turning it into a valuable tool for both the analysis of the reprogramming mechanism and the derivation of transgene-free iPS cells.
\end{abstract}

KEYWORDS: reprogramming, protein transduction, cell-penetrating peptide, factor-free iPS, Oct3/4, TAT

\section{Introduction}

The identification of induced pluripotent stem (iPS) cells by Yamanaka and co-workers (Takahashi and Yamanaka, 2006) is about to revolutionize modern life science. They showed that viral transduction of a limited set of transcription factors is sufficient to reprogram somatic cells to a pluripotent, embryonic stem (ES) cell-like state. Human iPS cells would represent the most attractive option for the derivation of pluripotent patient specific cells as no embryos or oocytes are required for their generation. By this, they are a thus far unattainable source for regenerative medicine and disease modeling (Kiskinis and Eggan, 2010). However, crucial safety issues have to be addressed in order to generate human iPS cells that are clinically useful. The classical iPS technique involves permanent genetic manipulation that may result in tumor formation (Jalving and Schepers, 2009; Kane et al., 2010).

Soon after identification of the viral reprogramming protocol in mouse cells (Takahashi and Yamanaka, 2006) and its adaptation to human cells (Takahashi et al., 2007b, Yu et al., 2007) the apparent unwanted side effects resulting from the viral integration were addressed by various strategies. Depending on the degree of genomic manipulation these can be divided into three classes (Fig. 1). Firstly, reprogramming can be achieved by techniques

\footnotetext{
Abbreviations used in this paper: CPP, cell-penetrating peptide; ES cell, embryonic stem cell; FCS, fetal calf serum; GFP, green fluorescent protein; iPS cell, induced pluripotent stem cell; MEF, murine embryonic fibroblast cells; NEAA, non-essential amino acids; SR, serum replacement.
}

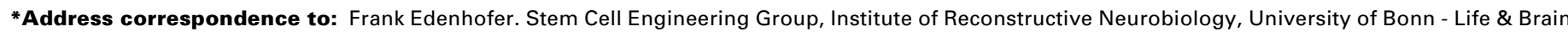
Center and Hertie Foundation, Sigmund-Freud Strasse 25, 53105 Bonn, Germany. Tel: +49-228-6885-529. Fax: +49-228-6885-531.

e-mail: f.edenhofer@uni-bonn.de -web: http://www.meb.uni-bonn.de/rnb/index.php?page=stem-cell-engineering
}

Final author corrected PDF published online: 16 February 2011.

ISSN: Online 1696-3547, Print 0214-6282 
that in fact first integrate the reprogramming transgenes. After iPS formation, a second round of genetic manipulation is needed to remove the transgenes. The Cre/loxP recombination system has been successfully employed to remove reprogramming factors from iPS cells (Fig. 1A) (Soldner et al., 2009; Sommer et al., 2009). In fact, the groundbreaking work by Takahashi and Yamanaka had already incorporated loxP-flanked reprogramming genes, however, Cre-mediated deletion failed in this case. This presumably was due to the high number of integration events and unwanted interchromosomal recombination of loxP sites. The use of polycistronic constructs minimizes the integration events and thereby favors successful deletion. Intriguingly, it has been shown that the residual presence of integrated reprogramming transgenes indeed has an impact on the developmental potential of iPS cells (Soldner et al., 2009; Sommer et al., 2009). A direct comparison of iPS cell clones before and after adenoviral Cre mediated deletion revealed significant improvement of the 'cleaned cells' to undergo specific differentiation in vitro and in vivo (Sommer et al., 2009). Notably, the Cre/loxP recombination mechanism entails a single loxP site, $34 \mathrm{bp}$ in size, remaining in the locus. The PiggyBac transposon system (Fig. 1B), in contrast, is able to de-integrate without genomic traces and has recently been applied to generate iPS cells of mouse and human origin
(Woltjen et al., 2009; Yusa et al., 2009; Ivics et al., 2009). Therefore, this strategy represents an attractive alternative to the use of Cre/loxP recombination system. A general concern with transposons is, however, that these might re-integrate instantly into another locus. Hence, further laborious and cumbersome genetic methods are needed to identify and confirm transgenefree iPS clones. To date, the factor excision strategy, either mediated by Cre/loxP recombination or transposase, represents the best compromise resulting in high reprogramming efficiencies while involving a relatively less-invasive cellular manipulation. In this respect the application of cell-permeant Cre recombinase (Peitz et al., 2002) (Nolden et al., 2006) might be instrumental since this would circumvent a second round of transfection needed for the excision of the transgenes. Indeed, we have recently observed that Cre protein transduction is highly efficient in removing reprogramming transgenes from iPS cells (unpublished observations).

In contrast to the first group, which still involves genomic integration, the second group of factor free strategies is characterized by non-integrating genetic manipulation of cells. Since a minimal window of eight days of transgene overexpression is needed for iPS derivation the straightforward approach of transient transfection of target cells with conventional plasmids is

\section{Factor excision}

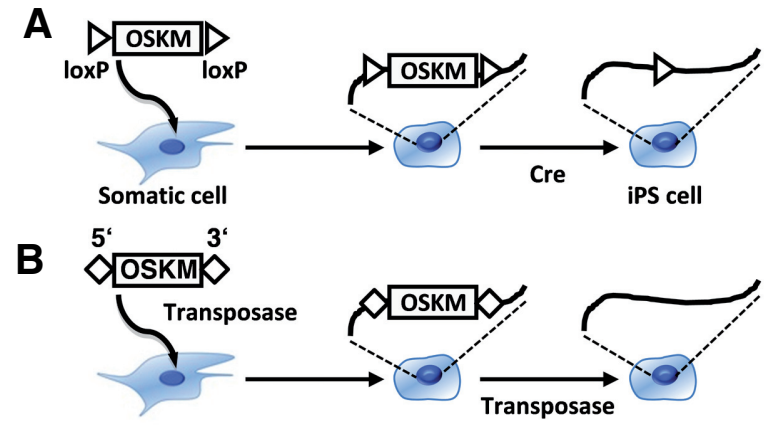

Fig. 1. Strategies for the generation of factor-free iPS cells. Various strategies can be applied to accomplish factorfree derivation of iPS cells. These can be categorized into three classes entailing (A,B) factor excision, (C-E) nonintegrating, and (F-H) non-genetic methods. (A) The Cre/ loxP recombination system can be used to delete repro-

gramming transgenes. To that end, transgenes flanked by two site-specific recombination recognition sites (loxP), are integrated e.g. by viral transduction and iPS cells are derived. In a second step, Cre recombinase plasmid is transfected to 'clean' the generated iPS cells. (B) The PiggyBac transposase enables integration and subsequent deletion of transgenes from iPS cells. In contrast to the Cre/loxP system, PiggyBac transposase leaves no trace in the genome. (C) Repetitive transient transfection of plasmids allows the expression of reprogramming transgenes over a long period of time. (D) The viral oriP/EBNA1 system can be used for the episomal stabilization of transgene-carrying plasmids under selection pressure. After iPS cell derivation, removal of selection pressure results in the loss of episomes. (E) Viruses that do not integrate into the host genome, such as Adenoand Sendai virus, have been used to derive iPS cells. Notably, non-integrating methods are usually less efficient than integrating strategies and must involve careful genetic analysis in order to confirm that genetic material did not integrate, since unwanted integration always occurs to a certain extent. (F) Small molecules that interfere with intracellular key signaling pathways may be used to induce pluripotency. Chemicals like histone-deacetylase inhibitors were identified enabling either the enhancement of iPS cell induction or the replacement of single reprogramming transgenes in a viral setting. Screening of compound libraries using appropriate cellular assays may identify new iPS modulators or replacers. (G) Repetitive lipofection of synthetic mRNA has been recently reported to yield iPS cells. (H) Protein transduction allows the direct delivery of proteins instead of gene delivery. The method involves engineering and purification of recombinant fusion proteins carrying so-called cell-penetrating peptides (CPP). Thus far, generation of iPS cells by protein delivery turned out to be very inefficient and not feasible with human adult fibroblasts. Further progress critically depends on the stabilization of the CPP fusion protein under cell culture conditions and the enhancement of endosomal release. 
insufficient. Repeated plasmid transfection (Fig. 1C) turned out to result in iPS colony formation albeit with a very low efficiency (Okita et al., 2008). Transfection of minicircle vectors lacking bacterial DNA and thus exhibiting high transfection efficiency and long ectopic expression were reported to reprogram human adipose stem cells (Jia et al., 2010). Another study exploited viral elements to episomally stabilize the reprogramming plasmids (Fig. 1D) (Yu et al., 2009). Moreover, the transduction with viruses that do not integrate their genome into host cells was applied (Fig. $1 \mathrm{E})$. Adenoviral vectors have been reported to reprogram mouse and human cells (Stadtfeld et al., 2008; Zhou et al., 2009). A Sendaivirus-based approach was recently reported to be successful in human iPS cell derivation (Fusaki et al., 2009).

From the safety perspective the third group of factor-free iPS induction would represent the most favorable group of reprogramming strategies since it entails no genetic manipulation at all. Small molecules (Fig. 1F) that are able to translocate into cells and interfere with signaling molecules have been identified to either enhance the process of reprogramming (Huangfu et al., 2008; Mikkelsen et al., 2008) or replace (Huangfu et al., 2008; Shi et al., 2008) single viral factors (for review see Feng et al., 2009). However, the search for small reprogramming molecules is largely empirical and a functional screening represents a significant hurdle to their identification since the validation of the cellular read-out is very complex. The direct delivery of either factorencoding mRNA (Fig. 1G) or reprogramming proteins (Fig. 1H) represents a more rational approach to achieve non-genetic iPS derivation (Bosnali and Edenhofer, 2008; Zhou et al., 2009; Warren et al., 2010). Given the already acquired knowledge of reprogramming genes and the projected role of the corresponding proteins encoded within, here, the challenge is to deliver a cocktail of biologically active proteins into cells.

So-called cell-penetrating peptides (CPPs) or protein transduction domains (PTDs) were reported to confer cell permeability when linked to cargo molecules (for review see (Brooks et al., 2005; Edenhofer, 2008; Gump and Dowdy, 2007). A highly basic CPP derived from the human immunodeficiency virus type 1 (HIV1) Tat (trans-activator of transcription) protein has mainly been applied in the literature based on the observation that the Tat protein is able to directly enter cells in culture and activate transcription of the viral genome (Frankel and Pabo, 1988; Green and Loewenstein, 1988). Over the past years a broad variety of molecules have been transduced into mammalian cells by direct delivery including oligonucleotides (Astriab-Fisher et al., 2000), fluorescent dyes (Bolton et al., 2000; Ho et al., 2001), peptides (Dostmann et al., 2000; Williams et al., 1997), proteins (Bosnali and Edenhofer, 2008; Peitz et al., 2002; Schwarze et al., 1999), antibodies (Cohen-Saidon et al., 2003; Heng and Cao, 2005),
Fig. 2. Enhancing protein stability of recombinant cell-permeant Oct4 fusion protein. (A) The stability of recombinant fusion protein as well as the endosomal release after cellular uptake represent limitations to the protein transduction technology. The capacity of media supplements like fetal calf serum (FCS), serum replacement (SR) and Albumax was analyzed to enhance the stability of recombinant cell-permeant Oct4 fusion protein Oct4-TAT. Depicted are Western blots of Oct4-TAT fusion protein-containing fractions dialyzed against (B) PBS, (C) KnockOut D-MEM, (D) D-MEM/F12, (E) KnockOut D-MEM supplemented with 5\% FCS and 2.5\% Albumax, (F) KnockOut D-MEM supplemented with $10 \%$ SR and $2.5 \%$ Albumax, (G) KnockOut D-MEM supplemented with $2 \%$ FCS, $7.5 \%$ SR and $2.5 \%$ Albumax (designated 'MT3' media) and incubated at $37^{\circ} \mathrm{C}$ for indicated periods of time. (H) Dialysis of Oct4-TAT protein against $20 \%$ sucrose results in concentration of recombinant factor. Dilutions of 1:10 and 1:20, respectively, into MT3 were incubated at $37^{\circ} \mathrm{C}$ for indicated periods of time and subsequently analyzed by immunoblotting. sucrose has been described to exert lysomotrophic activity thereby facilitating endosomal release. Western blot analysis was performed employing an anti-Oct4 antibody. E: elution fraction, i.e. protein fraction before dialysis; PBS: phosphate buffered saline; KO: KnockOut D-MEM; F12: D-MEM/F12; FCS: fetal calf serum; Alb: Albumax; SR: serum replacment; Glyc: glycerol stock.
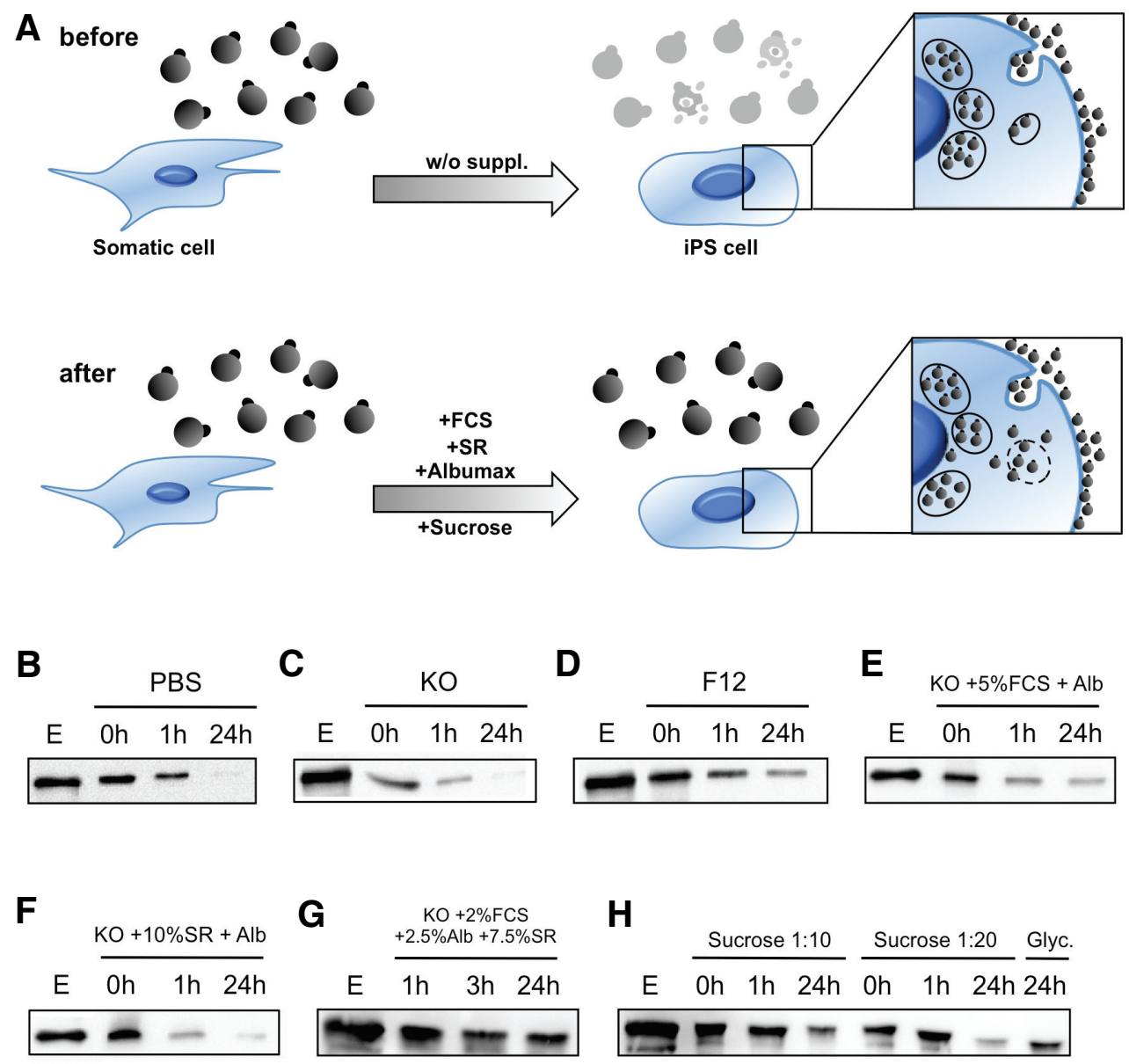
nanoparticles (Lewin et al., 2000) or liposomes (Torchilin et al., 2001). By this, various cellular processes have been successfully targeted by means of CPP-mediated protein transduction. For instance, manipulation of the cell cycle machinery has been accomplished by delivering biologically active p53 (Michiue et al., 2005; Snyder et al., 2005) and p27 (Nagahara et al., 1998). Protein transduction technology has been used to generate cellpenetrating versions of developmentally relevant transcription factors such as HoxB4 (Krosl et al., 2003), Pdx1 (Kwon et al., 2005), Scl (Landry et al., 2008), and Nkx2.2 (Stock et al., 2010). These applications demonstrated the feasibility to manipulate the differentiation potential of stem cells without ectopic gene expression. We previously reported the derivation of cell-permeant versions of recombinant reprogramming factors Oct4 and Sox2 (Bosnali and Edenhofer, 2008). These proteins turned out to specifically bind DNA such as the Oct4/Sox2 combined element in the Nanog promoter and compensated the RNAi-induced lossof-function of Oct4 and Sox2, respectively, by direct delivery into ES cells. More recently, Zhou et al. reported application of similar proteins for iPS derivation from mouse fibroblasts, albeit with an extremely low efficiency (Zhou et al., 2009). The recently reported use of ES cell extracts to induce pluripotency in murine fibroblasts (Cho et al., 2010) needs further investigation in order to demonstrate that it can be adapted to human cells as well.

In general, further development of protein transduction for cellular reprogramming, in particular its adaptation to reprogramming adult human fibroblasts, will greatly depend on overcoming the two major bottlenecks associated with protein transduction: stability of recombinant factors under cell culture conditions and endosomal release after cellular uptake. In this study we explore conditions for enhanced protein stabilization and delivery into somatic cells by systematically analyzing optimal culture and transduction conditions. We show that cellpermeant Oct4 protein can be stabilized by lipid-rich albumin supplements in serum replacement or low serum supplemented media. Employing optimized conditions for protein delivery, we demonstrate that Oct4 protein transduction is able to substitute for viral Oct4 delivery with an efficiency ranging in the same order of magnitude as a four virus approach.

\section{Results}

Improving protein stability of cellpermeant Oct4 fusion protein

The solubility as well as the stability of recombinant cell-permeant fusion proteins represent major chal- lenges for the derivation of a robust and efficient protein transduction system (Fig. 2A). We have previously shown that Oct4 can be purified from E.coli as a TAT-modified cell-permeant version, designated Oct4-TAT. Oct4-TAT was shown to specifically bind to DNA and to compensate for the RNAi-induced loss of activity in ES cells (Bosnali and Edenhofer, 2008). Any long term application that would be necessary to induce pluripotency in somatic cells, however, is hampered by the limited stability of the recombinant cell-permeant Oct4 fusion protein under physiological, i.e. cell culture conditions. Thus, we set out to optimize conditions for Oct4 protein transduction in order to be able to use it in a reprogramming assay. First we analyzed the influence of various basal media on the stability of extracellular Oct4-TAT. Oct4 fusion protein was dialyzed either against PBS, KnockOut D-MEM or D$\mathrm{MEM} / \mathrm{F} 12$. Western blot analysis was employed to determine the stability of the Oct4 fusion protein. In both, PBS and KnockOut DMEM, the recombinant protein is detectable after 1 hour of incubation at $37^{\circ} \mathrm{C}$. However, almost no signal is observed after 24 hours (Fig. 2 B,C). Dialysis against D-MEM/F12 yielded a stabilized fraction of the Oct4 fusion protein as judged by Western blot analysis after 24 hours of incubation (Fig. 2D). Moreover, serum components have been shown to stabilize recombinant fusion proteins in cell culture (Peitz et al., 2002) (Stock et al., 2010). Thus, we aimed at further stabilizing the Oct4 fusion
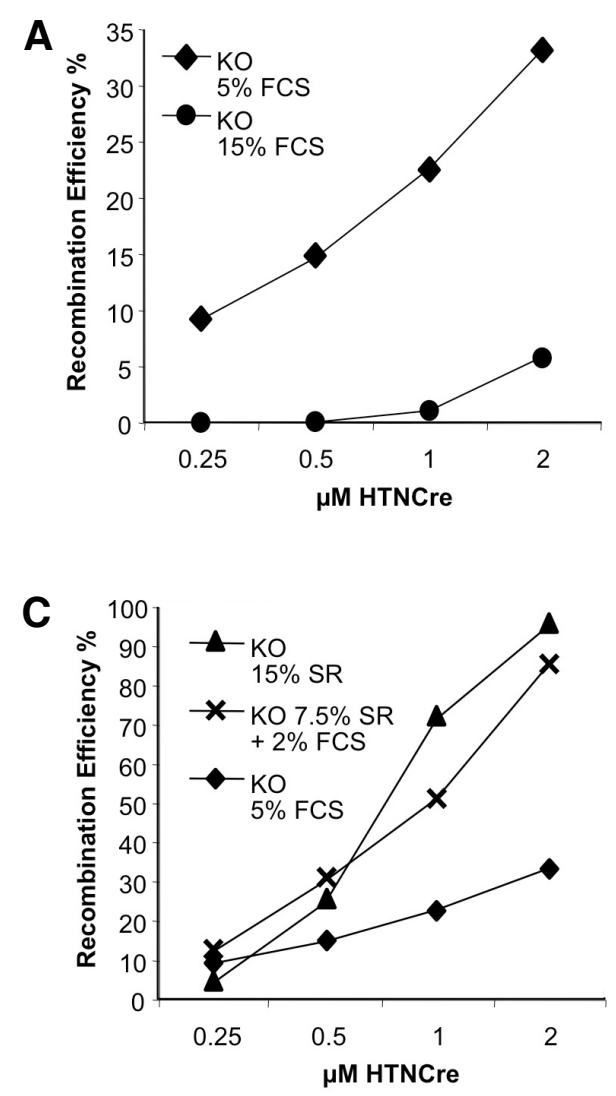

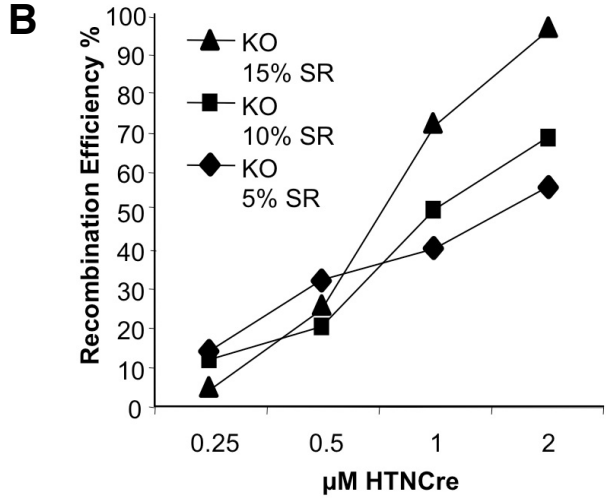

D

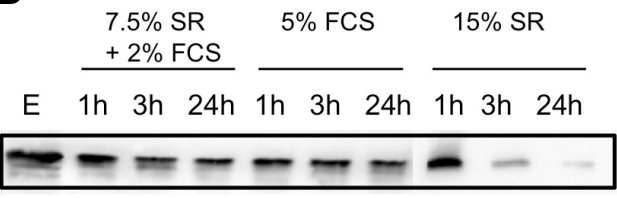

Fig. 3. Analysis of impact of media supplements on transduction efficiency employing the Cre protein transduction system. The influence of media supplements (A) FCS, (B) SR, and (C) combinations of both on the transduction efficiency was analyzed by protein transduction of Cre recombinase into the CV1-5B Cre reporter cell line. Cell-permeant Cre (HTNCre) was applied for 16 hours at concentrations indicated. Cells were fixed and stained for $\beta$-galactosidase activity using $X$-Gal. Recombinase efficiency was determined by counting blue cells and setting them into relation to total cell numbers. (D) Protein stability of Oct4-TAT in different media. Oct4-TAT-containing media were supplemented as specified and incubated under cell culture conditions for 1, 3 and 24 hours. Western blot analysis was performed employing an anti-Oct4 antibody. Elution fraction (E) served as a control. 
protein by supplementing the KnockOut D-MEM media with either fetal calf serum (FCS) or serum replacement (SR) (Mansfield et al., 2004) supplemented with Albumax. While FCS and SR alone turned out to exhibit only a minor effect on stabilization (Fig. 2 E,F) the combination of both resulted in significantly increased stability even after 24 hours (Fig. 2G).

Endosomal release represents a bottleneck for the intracellular delivery of translocated cell-permeant proteins. Several lysomotrophic agents including sucrose have been reported to interfere with endosomal integrity thereby facilitating endosomal release (Caron et al., 2004). Moreover, we anticipated that sucrose might allow the concentration of Oct4-TAT during dialysis as has been formerly described for dialysis against glycerol buffer (Bosnali and Edenhofer, 2008). Hence, we dialyzed Oct4 fusion protein against $20 \%$ sucrose buffer and found that purified Oct4TAT can be concentrated up to $500 \mu \mathrm{g} / \mathrm{ml}$ (Fig. 2H). This sucrosebased stock solution of Oct4-TAT allows storage at $-20^{\circ} \mathrm{C}$ and can conveniently be used on demand by directly diluting into the media of choice.

\section{Assessment of transduction capacity of various media using cell-permeant Cre}

As a matter of fact, the ideal protein transduction medium has to fulfill three main criteria: the stabilization of recombinant protein, the support of protein/cell-interaction to promote intracellular delivery, and compatibility to cell type(s) to be transduced. In the particular case of cellular reprogramming the fact that the cell type changes, thereby considerably increasing the complexity of media requirements, has to be taken into account. After identifying optimal conditions for the stabilization of the recombinant Oct4 fusion protein, we thus set out to analyze the extent to which the stabilizing supplements interfere with both the protein transduction process as such as well as with cellular reprogramming. To address the first question we used the well-established transduction read-out system based on a cell-permeant version of the DNA recombinase Cre developed in our laboratory, referred to as HTNCre (Peitz et al., 2002). A major feature of this protein transduction system is the fact that the efficiency of intracellular recombinase delivery can easily be quantified employing a Cre recombinase reporter line that has incorporated a Cre-dependent reporter gene. We used CV1-5B Cre reporter cells (Kellendonk et al., 1996) that express $\beta$-Galactosidase only after Cre-mediated recombination. Using this read-out system we first tested the influence of FCS on the transduction efficiency (Fig. 3A). We used $5 \%$ and $15 \%$ FCS, respectively, together with increasing concentrations of HTNCre. $2 \mu \mathrm{M}$ of HTNCre in $5 \%$ FCS-supplemented media induced recombination in approx. $35 \%$ of cells, whereas only $5 \%$ were recombined in medium containing $15 \%$ FCS. Lower concentrations of HTNCre such as $0.5 \mu \mathrm{M}$ still resulted in intracellular activity in about $15 \%$ of the cells in the presence of $5 \%$ FCS. However, the activity in cells treated with the same concentration in $15 \%$ FCS-supplemented medium was nearly undetectable, indicating a strong influence of FCS on the overall efficiency of protein transduction.

Next we assessed the influence of SR (Mansfield et al., 2004) on transduction efficiency using the same experimental setting. It turned out that in contrast to FCS increasing concentrations of SR positively correlate with increasing transduction efficiency, at least in the case of higher Cre concentrations (Fig. 3B). This result might be due to the fact that SR has a less broad proteinstabilizing spectrum compared to FCS. Consequently high concentrations of HTNCre (above $0.5 \mu \mathrm{M}$ ) might not be stabilized well by low serum replacement contents and therefore show less efficient transduction. Thus, a well-defined balance between protein stability and protein delivery is more critical in the case of

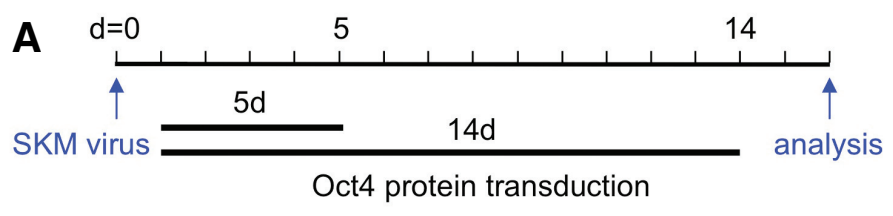

B

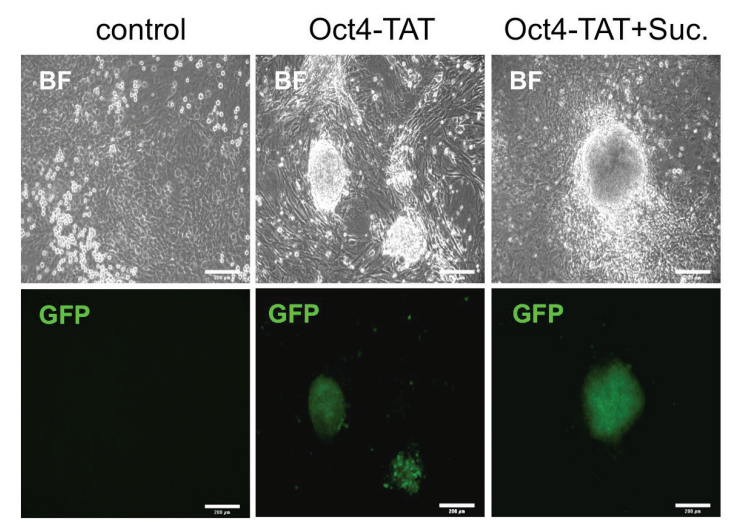

C

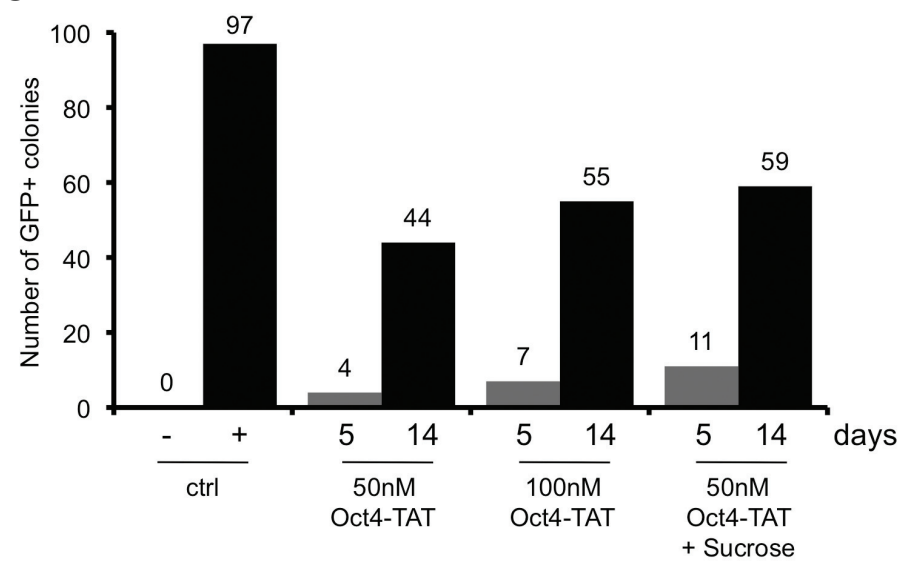

Fig. 4. Oct4 protein delivery substitutes for Oct4-encoding virus during reprogramming. (A) Schematic presentation showing the timeline of the experimental setting. Oct4-GiP MEFs were infected with viruses encoding Sox2, KIf4 and c-Myc (SKM) at day 0. Starting at day 1 post infection (p.i.), cells were incubated with Oct4-TAT for 5 and 14 days, respectively, changing the Oct4-TAT-supplemented media daily. (B) Representative pictures of cells transduced with Oct4 protein (50nM) displaying phase contrast (upper row) and GFP channel (lower row) 16 days p.i. sucrose (2\% final) was supplemented in one sample to enhance protein delivery (Oct4-TAT + Suc). Cells treated with medium only served as controls. Scale bar $=100 \mu \mathrm{m}$ (C) Quantification of GFP-positive colonies at day 16 p.i. demonstrating concentration and time-dependent effects of Oct4-TAT on the formation of GFP-positive colonies. 
A
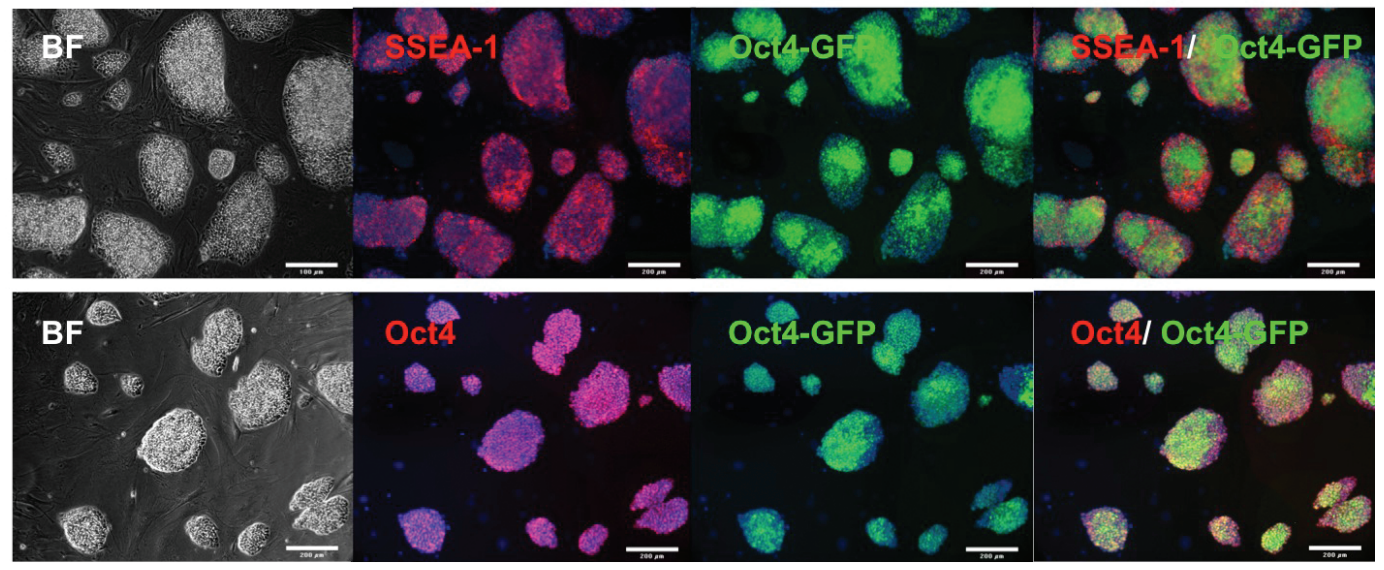

B

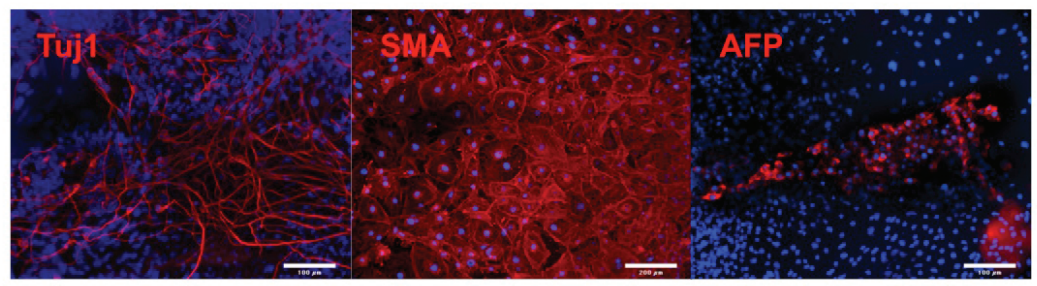

Fig. 5. Characterization of iPS clone derived from Oct4-TAT substitution. (A) Immunostaining for surface and nuclear pluripotency markers for iPS clone SucO1. The clone was generated from a substitution experiment in which Oct4-TAT-containing medium, derived from the sucrose stock (final conc. $2 \%)$, was applied for 5 days. The figure shows brightfield (BF), SSEA-1/ Oct4 immunostaining, Oct4-GFP transgene activity and overlay pictures, as indicated. DAPI co-staining was applied in every condition. Scale bar, 200 $\mu M$ (B) Immunostaining confirming the potential Oct4-TAT-iPS clone SucO-1 to differentiate into all the germ layers in vitro. Differentiated SucO-1 cells were stained for beta-III-tubulin (ectoderm), smooth muscle actin (SMA, Mesoderm) and alpha fetoprotein (AFP, endoderm) as indicated. DAPI costaining was performed in every condition. Scale bar, $100 \mu \mathrm{m}$.

use of the Oct4-GFP-transgenic MEFs (Ying et al., 2002) that become GFP-positive upon reprogramming serum replacement.

Compared even to the low FCS (5\%) containing medium, 15\% SR supplemented medium exhibit a 2 to 3 -fold higher transduction efficiency (Fig. 3 A,B). These data indicate that for intracellular protein delivery, SR is preferred over FCS. We then analyzed a medium supplemented with both FCS and SR. The content of serum components was tested on MEFs and murine ES cells using a medium supplemented with 5\% FCS and 15\% SR. Considering the FCS content to be critical, the percentage of FCS was reduced to the minimally tolerated concentration in a first step. Subsequently, the content of SR was adjusted likewise. By this, we identified $2 \%$ FCS and $7.5 \%$ SR (referred to as MT3 in the following) being minimally required to support growth of both cell types as well as maintaining ES cells in an undifferentiated state. Using the Cre reporter assay, MT3 medium showed a protein delivery capacity only slightly lower as compared to $15 \%$ SRsupplemented media; however, it was significantly higher than that of the 5\%-FCS supplemented medium (Fig. 3C). Moreover, Western blot analysis employing all three media revealed that MT3 supports stability of recombinant Oct4-TAT protein similar to FCS-supplemented (5\%) medium (Fig. 3D). In conclusion, these data demonstrate that beneficial effects of both supplements, FCS and SR, can be combined using a mixture of $2 \%$ FCS and $7.5 \%$ SR.

\section{Cell-permeant Oct4 protein substitutes for Oct4-encoding viral vector}

Next we assessed whether the optimized MT3 transduction medium would be able to fulfill the complex requirements needed to allow iPS generation from fibroblasts. Therefore we applied the classical four factor viral reprogramming paradigm and aimed at substituting the Oct4 virus by Oct4-TAT protein transduction employing MT3 conditions (Fig. 4A). As a target cell line we made to test two concentrations of Oct4-TAT protein in MT3 medium and one condition in which Oct4-TAT was diluted into MT3 from the $20 \%$ sucrose storage buffer. On day one after infection, cells were transduced with Oct4-TAT either for 5 or 14 days (Fig. 4A). We changed the protein-supplemented media every day to ensure a continuous delivery of recombinant reprogramming factor. The viral transduction of the three factors Sox2, KIf4, and c-Myc (SKM) alone did not yield any GFP-positive colony whereas additional protein transduction of Oct4 resulted in numerous GFP-positive colonies (Fig. 4B). GFP-positive colonies were quantified 16 days post infection. We counted 97 GFP-positive colonies in control dishes containing cells infected with all four viruses, whereas no single GFP-positive colony was observed in samples with SKM infection. The application of Oct4-TAT protein to SKM-infected cells yielded GFP-positive colonies in a concentration and time-dependent manner (Fig. 4C). While treating SKM-infected cells with $100 \mathrm{nM}$ Oct4-TAT protein for 5 days yielded rare GFP-positive colonies a continuous transduction of Oct4-TAT protein for 14 days increased the outcome more than 10-fold. Applying a higher concentration led to an enhanced formation of GFP-positive colonies, increasing numbers from 44 $(50 \mathrm{nM})$ to $55(100 \mathrm{nM})$. A further slight increase was detected in dishes where cells were transduced in the presence of sucrose. Under these optimized conditions the protein transduction of recombinant Oct4 in SKM-infected cells exhibits a reprogramming efficiency of about $60 \%$ in relation to the classical four factor (OSKM) virus protocol (Fig. 4C). To analyze whether protein substitution iPS cells could be expanded clonally and fulfill the criteria for pluripotency in vitro, iPS lines from all Oct4-TAT application conditions were generated. It turned out that even clones derived from short-term (5 days) and low (50 nM) Oct4TAT application could readily be expanded and showed characdue to the reactivation of the Oct4 promoter region. We decided 
teristic pluripotency marker expression (Fig. 5A). The differentiation potential in vitro was addressed by spontaneous differentiation employing an embryoid body paradigm (Fig. 5B). The clones analyzed gave rise to all three germ layers in a percentage similar to ES cell controls.

\section{Discussion}

The direct delivery of recombinant transcription factors represents a highly attractive strategy to derive transgene-free iPS cells. However, the stability of recombinant proteins and the endosomal release represent major bottlenecks for achieving robust and efficient reprogramming by protein transduction. Here we set out to elaborate an optimized protocol for the delivery of cell-permeant Oct4 protein by focusing on media supplements. The ideal transduction medium has to fulfill three major criteria: stabilization of recombinant protein, support of protein/cell-interaction to promote intracellular delivery, and compatibility to the needs of the cell types to be transduced. Purified cell-permeant Oct4 protein displays limited solubility and/or stability under cell culture conditions (Bosnali and Edenhofer, 2008). We show that a combination of $2 \%$ FCS and $7.5 \%$ SR (designated as MT3) is beneficial to enhance the stability of Oct4 fusion protein in the medium. Employing a robustly quantifiable Cre protein transduction system we observed that FCS strongly reduces the cellular uptake. Here, supplementation of SR is preferred over FCS since it strongly increases transduction efficiency although it shows lower protein stabilizing capacity compared to FCS. However, SR is not well tolerated by the fibroblast target cells. Transduction of Cre protein demonstrated that a mixture of $2 \%$ FCS and $7.5 \%$ SR strongly minimizes the transduction-inhibiting effect of FCS while providing transduction efficiencies similar to SR-only media. Thus, MT3 media represents an optimal compromise for cultivation during protein-induced reprogramming of fibroblasts.

Employing these optimized conditions the transduction of recombinant Oct4-TAT in SKM-infected fibroblast cells resulted in a reprogramming efficiency of about $60 \%$ relative to the classical four factor (OSKM) virus protocol. Furthermore stable Oct4-TATiPS cell lines can readily be generated and show pluripotent characteristics in respect to marker expression and differentiation potential in vitro. These data demonstrate that protein transduction of Oct4-TAT can substitute for viral delivery with efficiency ranging in the same order of magnitude observed when using the four viruses. Previous studies indicated that cellular reprogramming by recombinant proteins exhibits a very low efficiency, i.e. 3 colonies out of $5 \times 10^{4}$ cells (Zhou et al., 2009). Further investigations are needed to demonstrate that robust reprogramming of human adult fibroblast can be achieved employing recombinant proteins. In a non-genetic reprogramming context, we expect our transduction system to reach a thus far unattained level of control over reprogramming activity, turning it into a valuable tool for both the analysis of the reprogramming mechanism and the derivation of transgene-free iPS cells.

\section{Materials and Methods}

\section{Protein expression and purification}

pSESAME-Oct4 expression plasmid (Bosnali and Edenhofer, 2008) was transformed into E. coli BL21 (DE3) gold strain (Stratagene, La
Jolla, USA) by heat shock at $30^{\circ} \mathrm{C}$ and incubated for $1 \mathrm{~h}$ in SOC medium at $30^{\circ} \mathrm{C}$. Transformed bacteria were inoculated overnight at $30^{\circ} \mathrm{C}$ with shaking at $140 \mathrm{rpm}$ in LB medium containing $50 \mathrm{mg} / \mathrm{mL}$ carbenicillin. For protein expression the overnight culture was diluted 1:20 in TB medium (terrific broth) $/ 50 \mathrm{mg} / \mathrm{mL}$ ampicillin, $0.5 \%$ glucose and incubated at $37^{\circ} \mathrm{C}$ with shaking at $110 \mathrm{rpm}$ until OD600 reached 1.5. Protein expression was induced by IPTG at a final concentration of $0.5 \mathrm{mM}$. Cells were harvested by centrifugation and cell pellets were stored at $-20^{\circ} \mathrm{C}$.

For purification of His-tagged Oct4-TAT, cell pellets were thawed and resuspended in $20 \mathrm{~mL}$ of lysis buffer $(50 \mathrm{mM}$ Na2HPO4, $5 \mathrm{mM}$ Tris, $\mathrm{pH} 7.8,500 \mathrm{mM} \mathrm{NaCl}, 10 \mathrm{mM}$ imidazole) per $1 \mathrm{~L}$ of expression culture. Cells were lysed by application of $1 \mathrm{mg} / \mathrm{mL}$ lysozyme (Sigma, Deisenhofen, Germany), 10-15 U/mL Benzonase (Novagen, Darmstadt, Germany) and sonication. After centrifugation $(17.200 \mathrm{~g}, 20 \mathrm{~min})$ the cleared lysate was incubated with Ni-NTA agarose beads (Qiagen, Hilden, Germany) ( $1 \mathrm{~mL}$ of slurry for $1 \mathrm{~L}$ of bacterial expression culture) for $1 \mathrm{~h}$ with rotation at $4^{\circ} \mathrm{C}$. The slurry was packed into a column and washed with 8 column volumes of wash buffer $(50 \mathrm{mM} \mathrm{Na2HPO}, 5 \mathrm{mM}$ Tris, $\mathrm{pH} 7.8,500 \mathrm{mM} \mathrm{NaCl}$, and $90 \mathrm{mM}$ for Oct4-TAT). The protein was eluted with 3 column volumes of elution buffer $(50 \mathrm{mM} \mathrm{Na} 2 \mathrm{HPO} 4,5 \mathrm{mM}$ Tris, $\mathrm{pH} 7.8,500 \mathrm{mM} \mathrm{NaCl}, 250 \mathrm{mM}$ imidazole).

\section{Preparation of stock solution and transduction media}

For preparation of stock solutions the purified Oct4-TAT fraction was transferred to a $20 \%$ sucrose/PBS buffer by dialysis. After flash-freezing, Oct4-TAT could be stored at $-80^{\circ} \mathrm{C}$ and diluted into transduction media up to 1:5. Alternatively Oct4-TAT eluate fraction was dialyzed against DMEM/F12 or Knockout D-MEM (Invitrogen) over night at $4^{\circ} \mathrm{C}$. The next day the dialyzed fraction was diluted either to $50 \%$ or $25 \%$ with D-MEM/ F12 or Kockout D-MEM and supplemented with either i) 5\% FCS, $2.5 \%$ Albumax II $(200 \mathrm{mg} / \mathrm{mL}), 0.5 \%$ Insulin-Transferrine-Selenit (ITS, 100x, Invitrogen), $0.1 \mathrm{mM}$ non-essential amino acids (NEAA), $1 \mathrm{mM}$ sodium pyruvate, $2 \mathrm{mM} \mathrm{L}$-glutamine, $100 \mu \mathrm{M} \beta$-mercaptoethanol and $1000 \mathrm{U} / \mathrm{mL}$ LIF; or ii) $15 \%$ SR, $2.5 \%$ Albumax II $(200 \mathrm{mg} / \mathrm{ml}), 0.1 \mathrm{mM}$ NEAA, $1 \mathrm{mM}$ sodium pyruvate, $2 \mathrm{mM}$ L-glutamine, $100 \mu \mathrm{M} \beta$-mercaptoethanol and $1000 \mathrm{U} / \mathrm{mL}$ LIF; or iii) $2 \%$ FCS, $7.5 \%$ SR, $2.5 \%$ Albumax II $(200 \mathrm{mg} / \mathrm{mL})$, $0.5 \%$ ITS, $0.1 \mathrm{mM}$ non-essential amino acids, $1 \mathrm{mM}$ sodium pyruvate, $2 \mathrm{mM}$ L-glutamine, $100 \mu \mathrm{M} \beta$-mercaptoethanol and $1000 \mathrm{U} / \mathrm{mL}$ LIF. The mixture, either generated by direct dialysis or diluted from the sucrose buffer, was pre-conditioned in a water bath for $1 \mathrm{~h}$ at $37^{\circ} \mathrm{C}$ and cleared by centrifugation ( $5 \mathrm{~min}$ at $2500 \mathrm{~g}$ ) and sterile filtration. The protein concentration was determined by Bradford and/or dot blot assays.

\section{Cell culture}

Oct4-GiP MEFs (Ying et al., 2002) were cultured in high-glucose DMEM (Invitrogen) with 10\% FCS, $0.1 \mathrm{mM}$ NEAA, $1 \mathrm{mM}$ sodium pyruvate and $2 \mathrm{mM} \mathrm{L-glutamine.} \mathrm{MEFs} \mathrm{were} \mathrm{trypsinized} \mathrm{and} \mathrm{split} \mathrm{every} 4$ days and reseeded on tissue culture dishes coated with gelatin. For reprogramming assays MEFs were used to a maximum of passage 5 . For culture maintenance, mouse ES and iPS cells were cultivated in KnockOut DMEM (Invitrogen) with $15 \%$ SR, $0.1 \mathrm{mM}$ NEAA, $2 \mathrm{mM}$ glutamine, $100 \mu \mathrm{M} \beta$ mercaptoethanol and $1000 \mathrm{U} / \mathrm{mL}$ LIF. Cells were splitted every 3 days and cultivated on irradiated feeder cells.

\section{Retroviral infection and iPS induction}

Plasmids of pMXs-Oct3/4 (positive control), pMXs-Sox2, pMXs-c-Myc and pMXs-KIf4 were obtained from ADDGENE (Takahashi and Yamanaka, 2006). The Retroviruses were generated by the Plat $E$ packaging cell line as previously described (Takahashi et al., 2007a). Target cells were seeded at $10 \times 10^{4}$ cells per well in six-well plates. 24 hours after transfection the supernatant, comprising the viruses, was collected and filtered through a $0.45 \mu \mathrm{m}$ cellulose acetate filter. For substitution experiments and for negative controls Sox2, Klf4 and c-Myc were mixed in equal shares and supplemented with polybrene (Millipore) at a final concentra- 
tion of $4 \mu \mathrm{g} / \mathrm{mL}$. Positive controls additionally contained pMXs-Oct3/4 virus and were treated alike. Oct4-GiP cells were incubated with virus for 16 hours. Protein transduction experiments began after the virus-containing supernatant had been removed. After 5 days cells were split onto irradiated feeder cells. After 16 days cells were analyzed by fluorescence microscopy. For the purpose of generating stable iPS cell lines, cells were cultivated for 21 days under designated conditions. The colonies were then picked and expanded monoclonally.

\section{In vitro differentiation}

Cells were harvested by trypsination and transferred to petri dishes. Cells were grown in ES medium without the cytokine LIF for 3 days. The embryoid bodies generated were transferred to gelatine-coated tissue dishes afterwards and incubated for another 3 days. Immunostaining for the three germ layers was conducted with antibodies directed against Tuj1, smooth muscle actin and alpha fetoprotein.

\section{Acknowledgements}

We thank Austin Smith for providing us with the Oct4-GiP reporter line and Kathrin Vogt for excellent technical assistance. Also, we thank Hubert Schorle and Peter Kuckenberg (University of Bonn, Institute of Pathology) for help with mice breeding and Anke Leinhaas for MEF preparation. We are indebted to Michael Peitz, Kadari Asifiqbal and members of the Stem Cell Engineering Group for support and valuable discussions and critical reading of the manuscript. This work was supported by grants from the Deutsche Forschungsgemeinschaft DFG (ED79/1), the German Ministry of Education and Research, BMBF (01 GN 0813), and Merck KGaA, Darmstadt, Germany.

\section{References}

ASTRIAB-FISHER, A., SERGUEEV, D.S., FISHER, M., SHAW, B.R. and JULIANO, R.L. (2000). Antisense inhibition of P-glycoprotein expression using peptideoligonucleotide conjugates. Biochem Pharmacol 60: 83-90.

BOLTON, S.J., JONES, D.N., DARKER, J.G., EGGLESTON, D.S., HUNTER, A.J. and WALSH, F.S. (2000). Cellular uptake and spread of the cell-permeable peptide penetratin in adult rat brain. Eur J Neurosci 12: 2847-2855.

BOSNALI, M. and EDENHOFER, F. (2008). Generation of transducible versions of transcription factors Oct4 and Sox2. Biol Chem 389: 851-861.

BROOKS, H., LEBLEU, B. and VIVES, E. (2005). Tat peptide-mediated cellular delivery: back to basics. Adv Drug Deliv Rev 57: 559-577.

CARON, N.J., QUENNEVILLE, S.P. and TREMBLAY, J.P. (2004). Endosome disruption enhances the functional nuclear delivery of Tat-fusion proteins. Biochem Biophys Res Commun 319: 12-20.

CHO, H.J., LEE, C.S., KWON, Y.W., PAEK, J.S., LEE, S.H., HUR, J., LEE, E.J., ROH, T.Y., CHU, I.S., LEEM, S.H. et al. (2010). Induction of pluripotent stem cells from adult somatic cells by protein-based reprogramming without genetic manipulation. Blood 116: 386-395.

COHEN-SAIDON, C., NECHUSHTAN, H., KAHLON, S., LIVNI, N., NISSIM, A. and RAZIN, E. (2003). A novel strategy using single-chain antibody to show the importance of Bcl-2 in mast cell survival. Blood 102: 2506-2512.

DOSTMANN, W.R., TAYLOR, M.S., NICKL, C.K., BRAYDEN, J.E., FRANK, R. and TEGGE, W.J. (2000). Highly specific, membrane-permeant peptide blockers of cGMP-dependent protein kinase lalpha inhibit NO-induced cerebral dilation. Proc Natl Acad Sci USA 97: 14772-14777.

EDENHOFER, F. (2008). Protein transduction revisited: novel insights into the mechanism underlying intracellular delivery of proteins. Curr Pharm Des 14: 3628-3636

FENG, B., NG, J.H., HENG, J.C. and NG, H.H. (2009). Molecules that promote or enhance reprogramming of somatic cells to induced pluripotent stem cells. Cell Stem Cell 4: 301-312.

FRANKEL, A.D. and PABO, C.O. (1988). Cellular uptake of the tat protein from human immunodeficiency virus. Cell 55: 1189-1193.

FUSAKI, N., BAN, H., NISHIYAMA, A., SAEKI, K. and HASEGAWA, M. (2009).
Efficient induction of transgene-free human pluripotent stem cells using a vector based on Sendai virus, an RNA virus that does not integrate into the host genome. Proc Jpn Acad Ser B Phys Biol Sci 85: 348-362.

GREEN, M. and LOEWENSTEIN, P.M. (1988). Autonomous functional domains of chemically synthesized human immunodeficiency virus tat trans-activator protein. Cell 55: 1179-1188.

GUMP, J.M. and DOWDY, S.F. (2007). TAT transduction: the molecular mechanism and therapeutic prospects. Trends Mol Med 13: 443-448.

HENG, B.C. and CAO, T. (2005). Making cell-permeable antibodies (Transbody) through fusion of protein transduction domains (PTD) with single chain variable fragment (scFv) antibodies: potential advantages over antibodies expressed within the intracellular environment (Intrabody). Med Hypotheses 64: 11051108.

HO, A., SCHWARZE, S.R., MERMELSTEIN, S.J., WAKSMAN, G. and DOWDY, S.F. (2001). Synthetic protein transduction domains: enhanced transduction potential in vitro and in vivo. Cancer Res 61: 474-477.

HUANGFU, D., OSAFUNE, K., MAEHR, R., GUO, W., EIJKELENBOOM, A. CHEN, S., MUHLESTEIN, W. and MELTON, D.A. (2008). Induction of pluripotent stem cells from primary human fibroblasts with only Oct4 and Sox2. Nat Biotechnol 26: 1269-1275.

IVICS Z, LI MA, MÁTÉS L, BOEKE JD, NAGY A, BRADLEY A, IZSVÁK Z. (2009) Transposon-mediated genome manipulation in vertebrates. Nat. Methods 6 : 415-422.

JALVING, M. and SCHEPERS, H. (2009). Induced pluripotent stem cells: will they be safe? Curr Opin Mol Ther 11: 383-393.

JIA, F., WILSON, K.D., SUN, N., GUPTA, D.M., HUANG, M., LI, Z., PANETTA, N.J., CHEN, Z.Y., ROBBINS, R.C., KAY, M.A. et al. (2010). A nonviral minicircle vector for deriving human iPS cells. Nat Methods 7: 197-199.

KANE NM, NOWROUZI A, MUKHERJEE S, BLUNDELL MP, GREIG JA, LEE WK HOUSLAY MD, MILLIGAN G, MOUNTFORD JC, VON KALLE C. et al. (2010). Lentivirus-mediated reprogramming of somatic cells in the absence of transgenic transcription factors. Mol. Ther. 18: 2139-2145.

KELLENDONK C, TRONCHE F, MONAGHAN AP, ANGRAND PO, STEWART F, SCHÜTZ G. (1996). Regulation of Cre recombinase activity by the synthetic steroid RU 486. Nucl. Acids Res. 24:1404-1411.

KISKINIS, E. and EGGAN, K. (2010). Progress toward the clinical application of patient-specific pluripotent stem cells. J Clin Invest 120: 51-59.

KROSL, J., AUSTIN, P., BESLU, N., KROON, E., HUMPHRIES, R.K. and SAUVAGEAU, G. (2003). In vitro expansion of hematopoietic stem cells by recombinant TAT-HOXB4 protein. Nat Med 9: 1428-1432.

KWON, Y.D., OH, S.K., KIM, H.S., KU, S.Y., KIM, S.H., CHOI, Y.M. and MOON S.Y. (2005). Cellular manipulation of human embryonic stem cells by TATPDX1 protein transduction. Mol Ther 12: 28-32.

LANDRY JR, KINSTON S, KNEZEVIC K, DE BRUIJN MF, WILSON N, NOTTINGHAM WT, PEITZ M, EDENHOFER F, PIMANDA JE, OTTERSBACH K. et al. (2008). Runx genes are direct targets of Scl/Tal1 in the yolk sac and fetal liver. Blood. 111: 3005-3014.

LEWIN, M., CARLESSO, N., TUNG, C.H., TANG, X.W., CORY, D., SCADDEN, D.T. and WEISSLEDER, R. (2000). Tat peptide-derivatized magnetic nanoparticles allow in vivo tracking and recovery of progenitor cells. Nat Biotechnol 18: 410-414.

MANSFIELD, J.H., HARFE, B.D., NISSEN, R., OBENAUER, J., SRINEEL, J., CHAUDHURI, A., FARZAN-KASHANI, R., ZUKER, M., PASQUINELLI, A.E., RUVKUN, G. et al. (2004). MicroRNA-responsive 'sensor' transgenes uncove Hox-like and other developmentally regulated patterns of vertebrate microRNA expression. Nat Genet 36: 1079-1083.

MICHIUE, H., TOMIZAWA, K., MATSUSHITA, M., TAMIYA, T., LU, Y.F., ICHIKAWA, T., DATE, I. and MATSUI, H. (2005). Ubiquitination-resistant p53 protein transduction therapy facilitates anti-cancer effect on the growth of human malignant glioma cells. FEBS Lett 579: 3965-3969.

MIKKELSEN, T.S., HANNA, J., ZHANG, X., KU, M., WERNIG, M., SCHORDERET, P., BERNSTEIN, B.E., JAENISCH, R., LANDER, E.S. and MEISSNER, A. (2008). Dissecting direct reprogramming through integrative genomic analysis. Nature 454: 49-55.

NAGAHARA, H., VOCERO-AKBANI, A.M., SNYDER, E.L., HO, A., LATHAM, D.G. LISSY, N.A., BECKER-HAPAK, M., EZHEVSKY, S.A. and DOWDY, S.F. 
(1998). Transduction of full-length TAT fusion proteins into mammalian cells: TAT-p27Kip1 induces cell migration. Nat Med 4: 1449-1452.

NOLDEN, L., EDENHOFER, F., HAUPT, S., KOCH, P., WUNDERLICH, F.T., SIEMEN, H. and BRUSTLE, O. (2006). Site-specific recombination in human embryonic stem cells induced by cell-permeant Cre recombinase. Nat Methods 3: 461-467.

OKITA, K., NAKAGAWA, M., HYENJONG, H., ICHISAKA, T. and YAMANAKA, S. (2008). Generation of mouse induced pluripotent stem cells without viral vectors. Science 322: 949-953.

PEITZ, M., PFANNKUCHE, K., RAJEWSKY, K. and EDENHOFER, F. (2002). Ability of the hydrophobic FGF and basic TAT peptides to promote cellular uptake of recombinant $\mathrm{Cre}$ recombinase: a tool for efficient genetic engineering of mammalian genomes. Proc Natl Acad Sci USA 99: 4489-4494.

SCHWARZE, S.R., HO, A., VOCERO-AKBANI, A. and DOWDY, S.F. (1999). In vivo protein transduction: delivery of a biologically active protein into the mouse. Science 285: 1569-1572.

SHI, Y., DESPONTS, C., DO, J.T., HAHM, H.S., SCHOLER, H.R. and DING, S. (2008). Induction of pluripotent stem cells from mouse embryonic fibroblasts by Oct4 and Klf4 with small-molecule compounds. Cell Stem Cell 3: 568-574.

SNYDER, E.L., SAENZ, C.C., DENICOURT, C., MEADE, B.R., CUI, X.S., KAPLAN, I.M. and DOWDY, S.F. (2005). Enhanced targeting and killing of tumor cells expressing the $\mathrm{CXC}$ chemokine receptor 4 by transducible anticancer peptides. Cancer Res 65: 10646-10650.

SOLDNER, F., HOCKEMEYER, D., BEARD, C., GAO, Q., BELL, G.W., COOK, E.G., HARGUS, G., BLAK, A., COOPER, O., MITALIPOVA, M. et al. (2009). Parkinson's disease patient-derived induced pluripotent stem cells free of viral reprogramming factors. Cell 136: 964-977.

SOMMER, C.A., SOMMER, A.G., LONGMIRE, T.A., CHRISTODOULOU, C., THOMAS, D.D., GOSTISSA, M., ALT, F.W., MURPHY, G.J., KOTTON, D.N. and MOSTOSLAVSKY, G. (2009). Excision of reprogramming transgenes improves the differentiation potential of iPS cells generated with a single excisable vector. Stem Cells 28: 64-74.

STADTFELD, M., NAGAYA, M., UTIKAL, J., WEIR, G. and HOCHEDLINGER, K. (2008). Induced pluripotent stem cells generated without viral integration. Science 322: 945-949.

STOCK, K., NOLDEN, L., EDENHOFER, F., QUANDEL, T. and BRUSTLE, O. (2010). Transcription factor-based modulation of neural stem cell differentiation using direct protein transduction. Cell Mol Life Sci. 67: 2439-2449.

TAKAHASHI, K., OKITA, K., NAKAGAWA, M. and YAMANAKA, S. (2007a). Induction of pluripotent stem cells from fibroblast cultures. Nat Protoc 2: 3081-9.
TAKAHASHI, K., TANABE, K., OHNUKI, M., NARITA, M., ICHISAKA, T., TOMODA K. and YAMANAKA, S. (2007b). Induction of pluripotent stem cells from adult human fibroblasts by defined factors. Cell 131: 861-872.

TAKAHASHI, K. and YAMANAKA, S. (2006). Induction of pluripotent stem cells from mouse embryonic and adult fibroblast cultures by defined factors. Cell 126: 663-676.

TORCHILIN, V.P., RAMMOHAN, R., WEISSIG, V. and LEVCHENKO, T.S. (2001) TAT peptide on the surface of liposomes affords their efficient intracellular delivery even at low temperature and in the presence of metabolic inhibitors. Proc Natl Acad Sci USA 98: 8786-8791.

WARREN L, MANOS PD, AHFELDT T, LOH YH, LI H, LAU F, EBINA W, MANDAL PK, SMITH ZD, MEISSNER A et al. (2010). Highly efficient reprogramming to pluripotency and directed differentiation of human cells with synthetic modified mRNA. Cell Stem Cell 7: 618-630.

WILLIAMS, E.J., DUNICAN, D.J., GREEN, P.J., HOWELL, F.V., DEROSSI, D., WALSH, F.S. and DOHERTY, P. (1997). Selective inhibition of growth factorstimulated mitogenesis by a cell-permeable Grb2-binding peptide. J Biol Chem 272: 22349-22354.

WOLTJEN, K., MICHAEL, I.P., MOHSENI, P., DESAI, R., MILEIKOVSKY, M. HAMALAINEN, R., COWLING, R., WANG, W., LIU, P., GERTSENSTEIN, M. et al. (2009). piggyBac transposition reprograms fibroblasts to induced pluripotent stem cells. Nature 458: 715-716.

YING, Q.L., NICHOLS, J., EVANS, E.P. and SMITH, A.G. (2002). Changing potency by spontaneous fusion. Nature 416: 545-548.

YU, J., HU, K., SMUGA-OTTO, K., TIAN, S., STEWART, R., SLUKVIN, II and THOMSON, J.A. (2009). Human induced pluripotent stem cells free of vector and transgene sequences. Science 324: 797-801.

YU, J., VODYANIK, M.A., SMUGA-OTTO, K., ANTOSIEWICZ-BOURGET, J., FRANE, J.L., TIAN, S., NIE, J., JONSDOTTIR, G.A., RUOTTI, V., STEWART, R. et al. (2007). Induced pluripotent stem cell lines derived from human somatic cells. Science 318: 1917-1920.

YUSA, K., RAD, R., TAKEDA, J. and BRADLEY, A. (2009). Generation of transgene-free induced pluripotent mouse stem cells by the piggyBac transposon. Nat Methods 6: 363-369.

ZHOU, W., FREED, C.R. (2009). Adenoviral gene delivery can reprogram human fibroblasts to induced pluripotent stem cells. Stem Cells 27: 2667-2674.

ZHOU, H., WU, S., JOO, J.Y., ZHU, S., HAN, D.W., LIN, T., TRAUGER, S., BIEN, G., YAO, S., ZHU, Y. et al. (2009). Generation of induced pluripotent stem cells using recombinant proteins. Cell Stem Cell 4: 381-384. 


\section{Further Related Reading, published previously in the Int. J. Dev. Biol.}

See our recent Special Issue Placenta edited by Joan S. Hunt and Kent L. Thornburg at: http://www.ijdb.ehu.es/web/contents.php?vol=54\&issue=2-3

Feeder- and serum-free establishment and expansion of human induced pluripotent stem cells

Mehdi Totonchi, Adeleh Taei, Ali Seifinejad, Mohammadsharif Tabebordbar, Hassan Rassouli, Ali Farrokhi, Hamid Gourabi, Nasser Aghdami, Ghasem Hosseini-Salekdeh and Hossein Baharvand

Int. J. Dev. Biol. (2010) 54: 877-886

Analysis of SOX2 expression in developing human testis and germ cell neoplasia

Si B. Sonne, Rebecca M. Perrett, John E. Nielsen, Melissa A. Baxter, David M. Kristensen, Henrik Leffers, Neil A. Hanley and Ewa RajpertDe-Meyts

Int. J. Dev. Biol. (2010) 54: 755-760

Challenges and strategies for generating therapeutic patient-specific hemangioblasts and hematopoietic stem cells from human pluripotent stem cells

Ann Peters, Paul W. Burridge, Marina V. Pryzhkova, Michal A. Levine,Tea-Soon Park, Christopher Roxbury, Xuan Yuan, Bruno PÈault and

Elias T. Zambidis

Int. J. Dev. Biol. (2010) 54: 965-990

Mouse induced pluripotent stem cells

Eamon Geoghegan and Lucy Byrnes

Int. J. Dev. Biol. (2008) 52: 1015-1022

Pluripotency and differentiation in embryos and stem cells - Pavia, 17-18 January 2008

James A. Adjaye, Anne G. Byskov, Jose B. Cibelli, Ruggero De Maria, Stephen Minger, Maurilio Sampaolesi, Giuseppe Testa, Catherine Verfaillie, Magdalena Zernicka-Goetz, Hans Sch^ler, Michele Boiani, Nicola Crosetto and Carlo A. Redi

Int. J. Dev. Biol. (2008) 52: 801-809

5 yr ISI Impact Factor $(2009)=3.253$
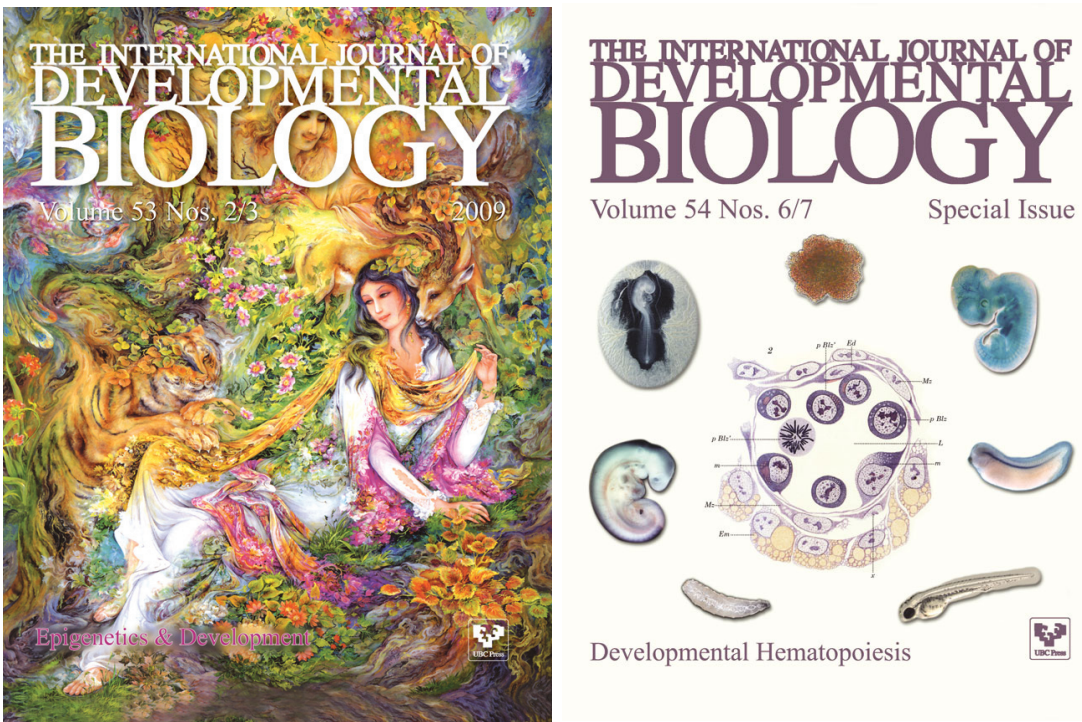

Volume 54 Nos. $6 / 7$

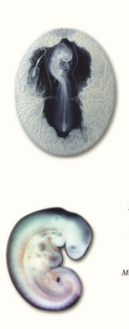

Developmental Hematopoiesis
Special Issue

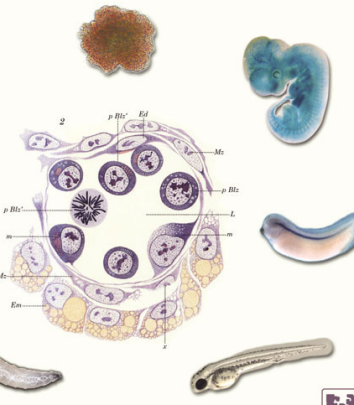

淁
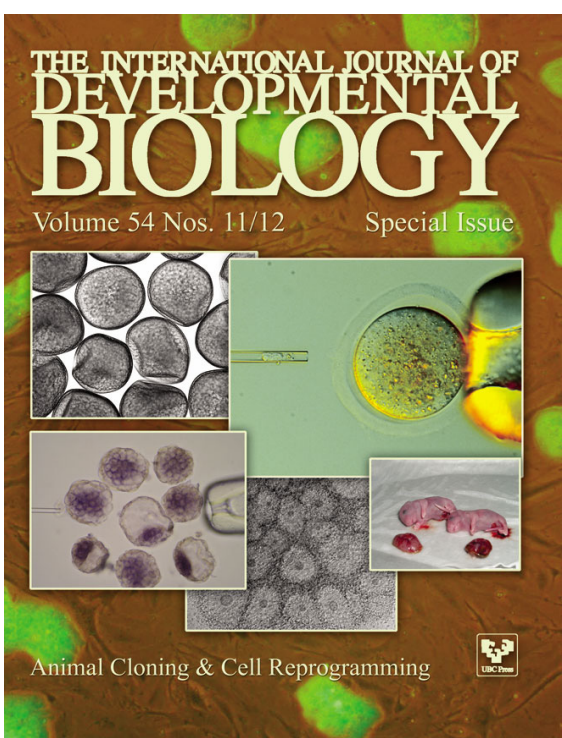